\title{
Language pedagogy in a pandemic: The shift to online instruction at a German university during the COVID-19 crisis
}

\author{
Donna J. Drucker ${ }^{1}$ and Karen Fleischhauer ${ }^{2}$ \\ ${ }^{1}$ Technische Universität Darmstadt, Germany (ORCID: 0000-0003-2932-8141) \\ ${ }^{2}$ Technische Universität Darmstadt, Germany (ORCID: 0000-0003-3492-4589)
}

\begin{abstract}
The focus of this research is the practicalities of adjustment to a semester of teaching language wholly online in the current COVID-19 pandemic at a German university. Such a study is important in order to illustrate the ways in which language instructors who were already proficient in teaching online were able to marshal existing resources and to develop new ones to assist their colleagues in developing skills in synchronous and asynchronous pedagogical modalities. The findings provide evidence that language instructors and students benefit somewhat from general technological instruction but much more from instruction that is combined with language pedagogy. The main conclusions drawn from this study are that intra-linguistic and cross-linguistic pedagogical exchanges fostered the successful execution of fully online teaching, and that online learning is more than just a digital replicate of learning in person. It requires its own set of digital and knowledge tools to be executed effectively.
\end{abstract}

Keywords: Language pedagogy; Language learning online; Second-language learning; Pandemic pedagogy; COVID-19 pedagogy

Article History: Submitted 13 December 2020; Revised 9 February 2021; Published online 24 February 2021

\section{Introduction}

On March 15, 2020, Technische Universität Darmstadt (TU-Darmstadt) in the state of Hessen, Germany, reacted to the COVID-19 crisis by cancelling the in-person final exams that were underway; directing all personnel to work from home if possible; and closing the campus's libraries, fitness centers, cafeterias, and meeting spaces (Brühl et al., 2020). The following day, the German government issued a statement that it was closing the country's borders (Der Spiegel "EU schließt," 2020). As it was clear that in-person teaching could not take place safely during the forthcoming summer semester, the university's leadership made a same-day announcement that all instruction would take place online, due to begin at the end of April (Hufeisen, 2020a). Amid the myriad life changes that came with trying to work and to stay healthy during a global pandemic, pedagogical adjustment was just one of them. We German and English instructors at an

Address of Corresponding Author

Donna J. Drucker, PhD, English as the Language of Instruction, Language Resource Centre, Technische Universität Darmstadt, Hochschulstr. 1, 64289 Darmstadt, Germany.

$\triangle$ donna.drucker@tu-darmstadt.de

How to cite: Drucker, D. J. \& Fleischhauer, K. (2021). Language pedagogy in a pandemic: The shift to online instruction at a German university during the COVID-19 crisis. Journal of Pedagogical Research, 5(1), 172-187. http://dx.doi.org/10.33902/JPR.2021167474 
engineering-focused university, like in-person educators around the world, had to rethink what kinds of teaching and learning were possible in a global crisis with no end in sight.

Unlike our US counterparts, though (we are both US citizens by birth), we did not have to alter our teaching in the middle of the semester - the March closures came during the university's vorlesungsfreie Zeit (the lecture-free pause between winter and summer semesters, when written and oral exams for required subjects take place). We had six weeks between the university's closure to all but essential personnel and the start of a two-week-delayed online semester to prepare. For instructors in the Language Resource Center (LRC), where we both work, this meant adjusting if not transforming manifold aspects of our approaches to course content, goal-setting, the balance between synchronous and asynchronous learning time, assessments, and feedback patterns. One of us needed to redo English classes alone, and the other needed to remodel language classes in both English and German. The guiding question for this article therefore is: how did German and English language teachers at a German university adjust to a fully online semester in the COVID-19 crisis?

This article describes the context, preparations, and teaching strategies that one experienced and one novice online instructor used to teach German and English to a largely engineeringoriented student body. First, it describes the context of language teaching at our university in summer semester 2020. Second, it provides a review of the pedagogical literature on which we based our course revisions. Third, it outlines our teaching preparations and the execution thereof in that semester. Fourth, we evaluate our performance to identify what elements of our teaching strategies worked well and which ones did not, including the results of student evaluations and a department-wide instructor survey. Finally, we provide recommendations to other instructors who will be teaching wholly online in the future in the context of an ongoing pandemic. We argue that a program of individual and group learning was critical toward establishing standards across the twenty languages taught at the LRC, the levels of languages taught, and the level of online expertise that instructors had prior to the summer semester. Specialized language-teaching instruction on Moodle, clarity on university-wide as well as departmental pedagogical standards and expectations, and peer-to-peer conversations were essential to providing professional structures for us all. However, there is room for improvement to adjust to a pedagogical situation in which all teachers and students are operating under stressful conditions.

\subsection{Background: COVID-19 at a German University}

As instructor, staff, and student safety cannot be guaranteed in in-person classrooms, we have been teaching remotely since April 2020. However, beginning in June, staff and faculty could return to their offices if they had a room to themselves (President of TU-Darmstadt, 2021). But whether students are learning in a classroom or at home, they all must meet university-wide language requirements. As of the winter semester 2019-2020, TU-Darmstadt had 25,170 undergraduate students and 4,118 graduate students (TU-Darmstadt "Facts," 2020). Students wishing to enter German-language degree programs must demonstrate a Common European Framework of Reference for Languages (CEFR) C1 level of German proficiency and a C1 level of English proficiency in English-language degree programs to qualify for admission. Students can prove those proficiencies through Goethe C1 or C2 certificates (German) or specific TOEFL (Test of English as a Foreign Language) or TOEIC (Test of English for International Communication) scores, among other official means (TU-Darmstadt "Application," 2020). Students demonstrating a C1-level of language proficiency can, among other skills, "understand a wide range of demanding, longer texts, and recognize implicit meaning...[They] can use language flexibly and effectively for social, academic and professional purposes" (Council of Europe, 2020). However, these programs do not require additional language classes once a student is admitted. Students take language classes voluntarily; when Drucker asks students on the first day of class why they take language classes, they say they want to improve their professional language skills, they have a good friend 
or partner who speaks the language, they are traveling or studying abroad for a semester, or that they want to meet new people.

Taking optional instead of required classes may not have been a priority for many students, but it remained so for some. In the last completed semester before the pandemic (Winter 2019-20), 1926 final grades in language classes were issued, with 662 in German-language classes and 472 in English-language classes. In the recently completed summer semester, 1576 final grades were issued, with 360 in German-language classes and 393 in English-language classes. ${ }^{2}$ That twenty percent enrollment drop in language classes may be due to the shift to online teaching, shrinking travel and study abroad opportunities, students choosing to take no or fewer optional classes, or uncertainty regarding when and how language certification exams will next take place. In addition, there was an enrollment drop across the university of international students who normally would have taken German classes in order to learn or to improve in the language. The international travel restrictions that were still in place when the semester began hampered international students' ability to study in Darmstadt.

\subsection{Literature Review}

For our online-only teaching and learning plans, we drew primarily on two books of broad pedagogical importance as well as specific guidance. The first of these books is McKeachie's Teaching Tips, now in its fourteenth edition. The advice of author Wilbert J. McKeachie and colleagues is especially useful because they teach at the Open University in England, which has conducted distance learning programs since 1971 (Open University, 2018). Given their experience with both face-to-face and distance learning, they did not perceive distance-learning methods as inherently less valuable face-to-face teaching: "Face-to-face teaching cannot be argued to be either necessary or sufficient for effective learning" (McKeachie, 1999). Co-author Diana Laurillard states the five conditions under which online teaching can take place effectively: 1) All students have access to the technology at appropriate places and times to use it; 2) Students have access to the specified software applications and resources they will need; 3) There is technical support available at study times for students who need it; 4) the department plans staff time appropriately for the requirements of the technology; and 5) there is staff development time and resources available to enable professors to develop their technological skills (McKeachie, 1999). Though Laurillard articulated these conditions in 1999, they remain the basis of determining whether or not instructors are properly equipped to teach online, and if students are prepared to learn online. These conditions were not met fully on either our or our students' sides, which we detail below. McKeachie and Laurillard value both pedagogical methods equally and provide advice for instructors on making the best of either method. They also outline the basic conditions under which online learning can happen successfully.

The second of these books is Kevin M. Gannon's Radical Hope: A Teaching Manifesto, which Gannon composed before the pandemic but published during one of its early peaks in April 2020. His analyses of pre-pandemic pedagogical challenges and how teaching can ameliorate them are extendable to the current crisis. He argues for a pedagogical praxis centered in "radical hope...one that fosters openness and inclusivity, critical reflection, dialogue and conversation, and a commitment to making higher education accessible and meaningful for all our students" (Gannon, 2020, p.6, emphasis in the original). As a means to achieve these goals, Gannon advocates Universal Design Learning (UDL), an approach to teaching that ensures all students, including those with disabilities, have access to materials and the opportunity to learn alongside their peers. For example, he points out that some need alternate accommodations for exams due to test-taking anxiety; visually impaired students need texts and images formatted to be readable for screenreader technology, and they needed subtitles added to spoken lectures for hearing-impaired students (Gannon, 2020). Finally, "the real work of change in higher education is done student by

${ }^{2}$ These statistics show the number of final grades entered, including participation-only (non-credit) grades. As some students take more than one class, they do not represent the total number of students taking language classes. 
student, classroom by classroom, course by course, and it's done by educators who have committed to teaching because it and their students matter" (Gannon, 2020, p.155). Gannon's perspective on accessible, student-centered learning, in which instructors guide students in a spirit of partnership, inspired many of us to be open and honest with our students about the difficulties of teaching and learning in a pandemic so that they could be open and honest with us as well.

Third, we gathered information on digital pedagogy that we could apply to teaching generally and teaching language specifically in a worldwide crisis. Our sources included guidebooks such as Teaching Online (Clandfield \& Hockly, 2017), Online Teaching at Its Best (Nilson \& Goodson, 2018), and Fremdsprache Deutsch Unterrichten [Teaching German as a Foreign Language] (Gehring, 2018). They also included articles from the online journal Hybrid Pedagogy for digital pedagogical framework concepts and the collection An Urgency of Teachers: The Work of Critical Digital Pedagogy (Morris \& Stommel, 2018; Morris \& Taub, 2018; Stommel 2020; Stommel et al., 2020; Van Overmeire, 2018). For example, a 2018 article on ethical online learning helped Drucker think more clearly about how to involve students actively in shaping their course experience, especially when they were originally expecting regular in-person courses: "Practicing collegial pedagogy in online learning means engaging students as pedagogical partners" (Morris \& Taub, 2018). Furthermore,

there is something different, something affectively different [about online teaching]. Most students taking fully online classes are doing so in relative solitude. In fact, they're counting on you to make not just the ideas in your class, the content the LMS [learning management system] is so content to deliver [and to] synthesize-they're also counting on you to make their experience of education synthesize (Morris \& Taub, 2018).

In other words, students may have been looking to us for more than just language instruction. It was likewise important to model patience for our students and each other, from the shoulders up, in order to create the best possible atmosphere for teaching and learning.

\section{Method}

\subsection{Participants}

There were two sets of participants in this project: full-time and adjunct instructors in the Language Resource Center and Drucker's and Fleischhauer's students. There were approximately seventeen full-time instructors (including Drucker and Fleischhauer) and forty-six adjunct instructors in the summer 2020 semester. Drucker had twenty-two students in her three classes (fourteen men, eight women) including eleven at the bachelor's degree level, eleven at the master's degree level, and none at the doctoral level. Fleischhauer had fifty-four (thirty-four men, twenty women) in her six classes, including seventeen at the bachelor's-degree level, thirty-six at the master's-degree level, and one at the doctoral level. We anonymized all participant data.

\subsection{Data Collection Process}

Since language teaching and exams take place only during the semester itself, the pandemic did not interrupt our teaching. As mentioned above, the TU-Darmstadt administration delayed the beginning of the semester by two weeks, so language instruction that normally takes place for thirteen weeks took place over twelve weeks in the summer semester. Language instructors, both full-time and adjunct, had six weeks to re-plan their courses and to adapt to online-only methods and techniques (adjuncts also had the option to cancel their classes). This re-planning and the subsequent execution thereof had three facets: the technological facet, the overall pedagogical facet, and the administrative and student-interaction facet.

First, regarding technological needs, members of the university's Center for Educational Development and Technology (HDA) paired with their counterparts at the University IT-Service and Computing Center (HRZ) to offer general online teaching suggestions and courses across the university, and guides to Moodle had been available for several years. However, Fleischhauer and the three other colleagues who comprised the LRC E-Learning team identified a clear need for further training in pedagogical techniques and specialized models for language learners and 
instructors alike (Kontinuum, 2017). As many staff members were already working from their home offices, the first priority was to establish a central, transparent means of communication amongst LRC staff. First, the E-Learning team established an asynchronous staff meeting place using the existing campus learning management system (LMS), Moodle. There were several clear advantages of using this platform. Communication among staff members could take place on several levels, due to the variety of functions available with the LMS. We could inform one another of important changes and new information via a news feed; all colleagues could pose questions, request help, and give one another help with instructional issues involving synchronous and asynchronous learning situations via a forum. Within separate thematic areas (language pedagogy, synchronous platforms, and exams, for example), they were able to inform colleagues about the various types of platforms usable for instructional purposes; colleagues could sign up for in-house workshops on asynchronous and synchronous learning platforms as well as other events designed and hosted by the E-Learning team; and the E-Learning team could also post surveys related to elearning and receive feedback from colleagues. The LMS was not only multifaceted, but it also proved to be flexible and efficient, as time was of the essence once we recognized the amount of work that lay ahead before the semester began. The placement of themes that became more or less important throughout the semester could be easily changed. In addition, new themes (i.e. testing) could be added as they gained importance as the semester progressed. The three main themes covered in the internal staff LMS were:

- Content-based exchanges among colleagues (forum)

- Technical issues related to online synchronous language instruction

- Technical issues related to online asynchronous language instruction

Due to the flexibility and multiple uses of the LMS, we were able to avoid unnecessary additional communication channels, as might have been the case if we had chosen e-mail as a means of contacting one another.

The E-Learning team's initial and most important goal was to have all colleagues trained in synchronous online learning systems, so that they would be able to hold online instruction at the beginning of the semester. In practice, most colleagues used Zoom for synchronous language instruction, as the university recommended it; a handful preferred Skype. Over the course of several weeks, the E-Learning team offered a series of workshops for a total of around ninety colleagues (including full-time and adjunct instructors), all of whom had little or no prior experience with Zoom. The first workshop served as a basic introduction to Zoom, its main features, and its use in the language learning classroom. Although the primary focus was to acquaint participants with the technical features of Zoom, the application of these features for instructional purposes in a language learning setting was a continuous point of reference in examples and hands-on tasks through the workshop. The workshops lasted ninety minutes on average. Workshops were held at three different times of day in order to accommodate colleagues' work and family schedules. The workshops that followed were primarily hands-on and based on the questions and individual needs of the participants, as they were planning and adjusting their course methodology plan to meet the needs of the upcoming online semester. During these workshops, colleagues learned one or two new, more advanced features of Zoom, after which they took turns assuming the host or learner role in the meeting room. Through online discussion and a clear and open collaborative effort among colleagues, we were able to tailor the program to our individual language instruction needs.

In addition to these workshops, the E-Learning team also simulated and recorded an online instructional session and posted this on our staff LMS. Here, it was possible to see how technical features of Zoom were being used; however, the primary focus was to gain an understanding of how Zoom could be best used for instructional purposes in the language learning classroom. This important aspect set our workshops and materials apart from other information available online, as the language learning setting guided our decision-making and the generation of our ideas. This 
is perhaps why our colleagues felt so comfortable with Zoom and were given overwhelmingly positive feedback from students in university-wide evaluations when the semester was over.

Second, regarding the overall pedagogical facet, most colleagues used Moodle for asynchronous instruction. Prior to the pandemic, most of us had only used it for administrative purposes such as posting homework, uploading documents, and providing links to websites with instructionrelated (language-learning) material, however not for interactive purposes. Unlike Zoom learning workshops, for which all participants needed an initial technical overview of the program's features, many colleagues already had a basic understanding of Moodle, and so the E-Learning team's Moodle workshops focused on those interactive purposes. Separate workshops for beginners and for colleagues with prior experience were offered over the course of several weeks before the semester began. Areas in which there was interest but relatively little or no prior experience included various test functions; the survey function; how to give feedback; how to use the glossary; and how to use Etherpad (a real-time, collaborative text editor plugin). All of those functions focused on enabling a more interactive and collaborative online learning experience for our instructors and for our students.

The E-Learning team also recorded and uploaded videos on various topics related to the design of language classes on Moodle to our staff LMS. Open office hours were held on a weekly basis, during which colleagues could address individual problems or issues in course planning or incidents that occurred during the semester. In addition, a sample Moodle course was put into place, so that colleagues could visualize what a fully developed Moodle course page looked like. Of course, new issues would continue to arise as the semester began. These were discussed in our online forum and in informal weekly staff meetings (Stammtisch in German) via Zoom. For example, one instructor posted a query in the staff forum about PowerPoint presentations. She asked if there were additional tools to make videos of her presentations that could eventually include animations and subtitles, and if anyone could share examples of how they used such tools. One of the E-Learning team members suggested Camtasia, which the university's IT-Service and Computing Center also supported. Simple as such an exchange was, the ability of other instructors to see it saved the E-Learning team from having to answer the same question repeatedly. Such posts could indirectly help a greater number of colleagues at one time, as all had access to the same information.

Despite the importance of asynchronous and synchronous technological tools, they remained secondary to the didactics of language learning that underpinned them. Although it was clear that we would need both tools (Moodle and Zoom) for the digital semester, we recognized that the amount of asynchronous and synchronous elements could differ depending on multiple factors. These included language level, course theme (i.e., a writing course versus a conversation course), hours of instruction, days per week the class was being held, number of class participants, and language (i.e., How will the learners produce language in the digital classroom - especially with languages using special characters?).

The E-Learning team compiled their initial suggestions into a document called "Recommendations for Digital Teaching" in early April, posted depictions of these different scenarios on the instructor LMS, and elaborated on them in formal and informal staff meetings. The "Recommendations" document outlined several options for blending asynchronous and synchronous platforms, outlining the advantages and disadvantages of each. It suggested that instructors limit the synchronous meeting time to forty-five minutes and the number of students in a synchronous meeting to fifteen. If the class was larger than fifteen students, the instructor ideally divided the students into two groups and held two separate forty-five-minute meetings. In general, most beginner-level courses (CEFR A1-B1, UNIcert ${ }^{\circledR}$ I) used synchronous and asynchronous elements equally. Other higher-level courses, in contrast, such as writing courses (CEFR B2-C1, UNIcert ${ }^{\circledR}$ II and III), met every two weeks for synchronous sessions (Arbeitskreis, "Niveaustufenbeschreibung Englisch," 2017). In the latter courses, instructors assigned weekly writing tasks on Moodle. The E-Learning team did not make recommendations about homework 
assignments, midterms, or final exams; however, staff members discussed these topics in formal and informal staff meetings. Finally, the LRC Moodle page offered an "Online Netiquette" guide and checklist of key elements for online course preparation so that we could see at a glance if we had prepared for all of them. These elements included technology requirements, organizational elements within the synchronous meeting, the preparation of course materials ahead of time, methods and didactics, and turning on the non-verbal elements of Zoom (thumbs-up, handraising, and applause features). The "Online Netiquette" guide stated that students should turn their cameras on and keep them on throughout the synchronous class period, but in case their Internet connections were poor, they could turn their cameras off and could participate via voice only.

Third and last, there were new administrative and interpersonal conduct facets to manage for both instructors and students. This manifested in an e-learning agreement that crystalized the new situation for everyone. The E-Learning team prepared an e-learning agreement in both English and German that students could sign. This e-learning agreement formalized and detailed parameters for online learning under four subheadings: digital teaching, attendance and absence, assessment and testing, and student autonomy. On the one hand, some of the agreement's requirements were similar to those that instructors regularly had for in-person classes, such as "Get familiar in advance with the structure and schedule of your language course. Your instructor(s) will provide you with the necessary information." On the other hand, the agreement acknowledged the difficulties of the new situation: "Learning on-line will be quite a challenge both to you and the instructor(s). Because of that, we kindly ask you to fully focus on the face-to-face on-line course session and not let yourself be distracted by social media messaging." Students were responsible for more self-study and preparation in advance of the Zoom or Skype meetings, as the synchronous parts of the course would be shorter than a standard hour-and-forty-minute inperson class. The agreement also included technological specifications, such as requesting students to use headphones, to turn on their video as well as audio connections if possible, and to mute themselves unless they were speaking to minimize background noise. Furthermore, the e-learning agreement stated that attendance was mandatory, though students could miss up to two classes if they were ill or taking care of an ill person without a penalty to their grade. ${ }^{3}$

Signing the agreement was not required for participation, but most students signed it anyway to indicate their acceptance of the new situation formally. All in all, even though no one knew exactly how the pandemic would unfold in Germany, students and instructors could move forward together with these parameters in place by the time the summer semester started in late April.

\subsection{Data Analysis}

We used qualitative analytic methods to study our data. We gathered our primary-source data from instructors who led and participated in workshops with the E-Learning team, student feedback during our courses, student course evaluations, and surveys of full-time and adjunct instructors conducted before and near the end of the semester. We also incorporated material from our own course preparations and exams; records of our own experiences during synchronous teaching sessions and moderating asynchronous activities; e-mails and direct messages from students; the E-Learning team's workshops and informal meetings; and records of conversations with our colleagues and each other. We organized these materials when exams were complete, identified common themes and chronologies, and brought them together to create a picture of pedagogical development and change across the semester.

\footnotetext{
${ }^{3}$ Some of Drucker's students e-mailed her their class notes and answers to the study questions voluntarily if they had technical
} difficulties or were unable to attend class. She provided feedback via a reply message. 


\section{Results}

Based on the background literature described above and the collegial instruction provided, the two of us reoriented our language pedagogy to this online-only situation. Our pedagogical decisions differed according to our levels of experience, previous background in online teaching methods, and the language levels taught. As Fleischhauer was more experienced in LMS use and online teaching, she could adapt her existing digital methods more smoothly into an online-only format. As Drucker had less language pedagogy experience and little online teaching experience - prior to the 2020 semester, she used e-mail for communication and assignment submission and Dropbox for document sharing-she had to overhaul her approach to technology use in the classroom. However, both of us had to adjust our methods as the semester moved forward, as we observed which practices worked well for all-online learning and which ones did not.

Fleischhauer taught three English classes and three German classes. Her first English class was "Writing as an Engineer" at the UNIcert® III level, an intensive course that introduces students to the different kinds of writing that professional engineers produce, including e-mails, technical reports, and technical specifications. The second, at the UNIcert ${ }^{\circledR}$ II level, was "English for Engineers" and covered three of the four areas of language development: speaking, writing and listening. The third course centered on academic writing and was also held at the UNIcert ${ }^{\circledR}$ II level. The first German class was an advanced beginner class at the UNIcert ${ }^{\circledR}$ I (CEFR B1) level, the second was a writing and discussion class at the UNIcert ${ }^{\circledR}$ II level, and the third was an introduction to technical communication in engineering and natural sciences (speaking, reading, and listening) at the UNIcert@ II level.

In terms of course preparation, Fleischhauer, who was experienced in online pedagogy, was able to draw upon existing digital materials that she had already developed and implemented in previous semesters. However, due to the new mix of synchronous and asynchronous elements in these classes, the existing materials also required some adjustments. Some of the most important adjustments included: reallocation of learning goals and tasks between the synchronous and asynchronous learning environments; a more detailed lesson plan for the synchronous sessions; and a greater integration of non-verbal communication forms during synchronous sessions. These adjustments depended on the class size as well as the language level.

For example, regarding Fleischhauer's first major adjustment, an advanced beginner German language class with 20 learners held once per week for a total of 180 minutes was now divided into two 90-minute sessions. One-half of the students participated in the synchronous session via Zoom. After a short break, that half of the students began the remaining 90 minutes of instruction on Moodle, where they had two or three tasks to complete in that time, many of which were collaborative. The other half of the class began with the Moodle session and then entered the synchronous session for the second 90-minute period. The primary goals of the synchronous sessions were to have the students speak as much as possible and to gain a deeper understanding of key grammar topics.

As preparation for class each week, students were required to complete homework assignments made available on the course Moodle page. Fleischhauer could easily and closely follow student progress, as all assignments were made available and submitted on Moodle. The assignments covered core language learning areas (reading, writing, listening and grammar, as well as vocabulary and speaking). Some tasks required students to submit an audio file, made possible by the features available in Moodle and followed the flipped-classroom principle. That is, the students were required to come prepared to class each week and did so by completing the given assignments on Moodle. Since students came somewhat thematically prepared to synchronous sessions, Fleischhauer was able to focus much more on speaking exercises, which integrated the knowledge that students had newly gained from the preparatory assignments. Students were able to talk about the themes in more detail, as they had time to learn certain terms and to apply them in exercises on Moodle before online Zoom sessions. 
Another sub-goal of the synchronous sessions was for students to gain a deeper understanding of key grammar topics. Here, Fleischhauer followed in large part the same procedure each week, using a PowerPoint template with a list of example sentences, which students had to stamp as true or false. By stamping their answer - which they could do simultaneously in Zoom - all students were able to respond to questions at the same time. Likewise, Fleischhauer could see instantly how well the students understood the main grammar concepts. She could then provide a brief explanation of grammatical rules or lead students in more advanced exercises, depending on their level of understanding.

Figure 1

Fleischhauer and students in a German-language class working on a stamping activity, June 2020. Courtesy Fleischhauer

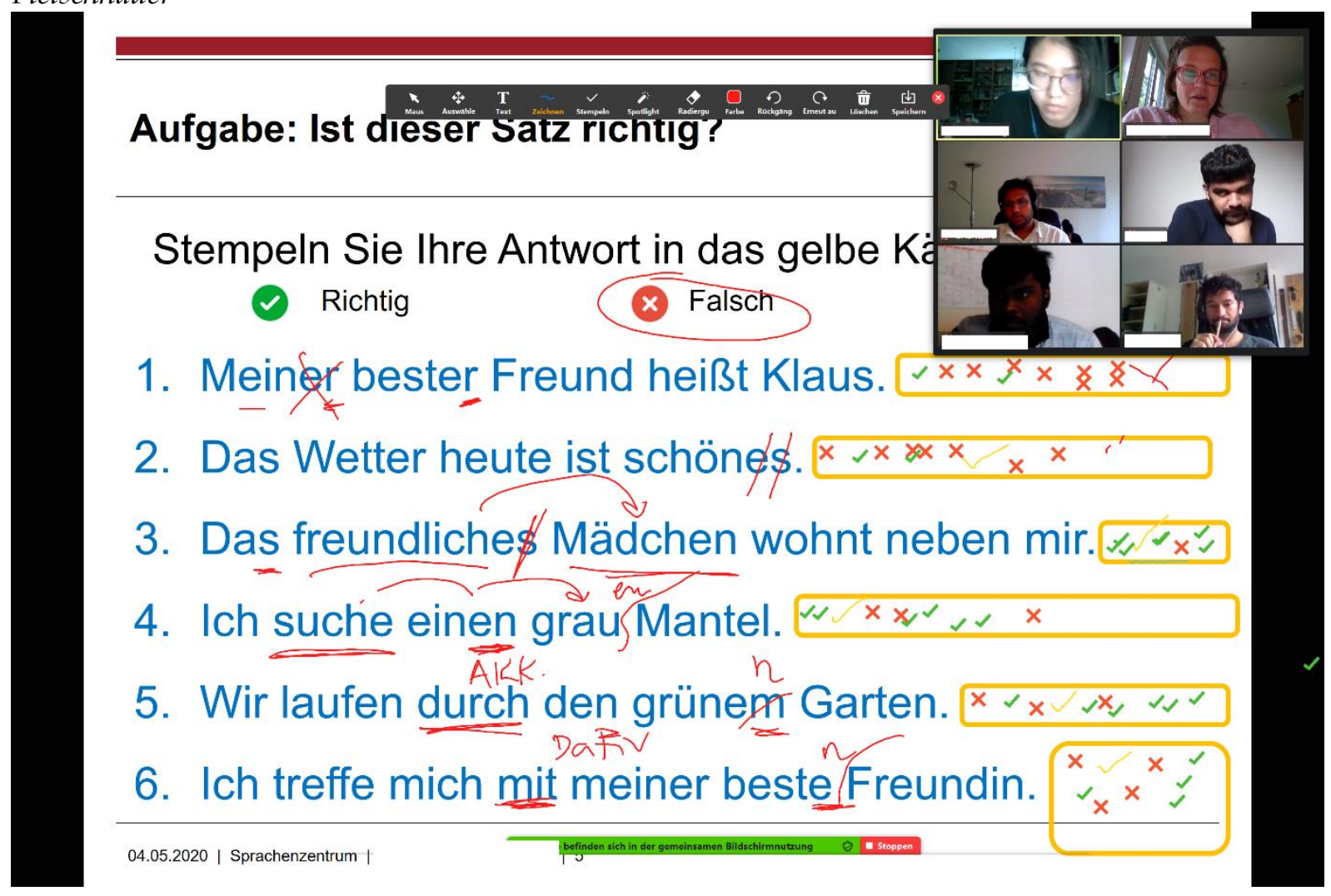

Fleischhauer's second major adjustment was a more detailed lesson plan for the synchronous sessions. This was especially the case for larger language courses, such as "English for Engineers," which had over twenty students at the beginning of the semester. This course was also divided into two groups, with class time split between synchronous and asynchronous sessions. Unlike the advanced German beginner course, the total course time was limited to ninety minutes per week. In order to optimize the time spent in both sessions, Fleischhauer planned all lessons in more detail and paid greater attention to staying within the timeframe. In a period of forty-five minutes, a total of three group activities were possible. These often included tasks that students solved together in breakout sessions. In plenum, they would report briefly on their results. In summary, smaller, compact themes structured the synchronous sessions. Students then continued practicing via thematically related exercises in vocabulary, reading, listening and grammar on the Moodle course page during the asynchronous segment of class, held during regular scheduled class time.

The third important adjustment in digital instruction for Fleischhauer was the use of nonverbal forms of communication in synchronous instruction. These proved to be quite effective in all classes; however, they were especially useful in larger classes, as they enabled all students to communicate at the same time. Several non-verbal forms of communication are integrated in 
Zoom and offer teachers and students a wide variety of tools: stamps (yes, no, positive/negative, etc.), highlighters, markers, and geometric figures, just to mention a few. Students often used the text function (with a Whiteboard or another shared text in the background) to express their knowledge or opinion about engineering-related topics. As was the case with the stamp function, all students could enter their answer simultaneously. Fleischhauer was able to respond to the students' texts and to continue the dialog as the students continued to write. The non-verbals proved effective for learners as well as for instructors.

Drucker, a novice user of digital pedagogy methods, taught three English classes at the UNIcert ${ }^{\circledR}$ III level: English for Social Sciences, English for Science, and Advanced Oral Communication for Science and Humanities. Given the new format and teaching circumstances, Drucker organized all three classes the same way to streamline her semester-long planning and organization. The English for Social Sciences class addressed the theme of food sustainability, the English for Science class focused on a set of readings from the September 2018 issue of the popular magazine Scientific American on human origins, and the Advanced Oral Communication class centered on the theme of human travel to Mars. Each one met synchronously for one hour per week, a slightly longer period than the E-Learning team's recommendations, with an assigned reading on the class theme for each meeting.

Drucker began the synchronous sessions of her classes by asking students free-form questions about the texts. She realized within the first two weeks, though, that students were more responsive if they had some fixed questions to prepare ahead of time and then felt better prepared to answer follow-up or spontaneous questions immediately afterward. So, several days before each session, she posted three types of study questions about the assigned reading on the class Moodle page, divided evenly between factual, application and interpretation, and problem questions (McKeachie, 1999). As each student was required to participate orally at least once in each synchronous session (see assessment below), being able to prepare questions ahead of time was especially helpful for shyer or more nervous students (McKeachie, 1999). She also asked students if there were specific skills that they wanted to work on and developed fifteen-minute mini-lessons on topics such as paragraph construction in essays and the proper use of punctuation, specifically commas. Even on a small level, asking students about their learning interests and then creating lessons based on them are actions based on the recognition that "online learning [is] a coproduction, collaboratively and jointly produced by teachers and learners. This means consulting with students about course topics, involving them centrally in choices about what they research in a class" (Morris \& Taub, 2018). In the next section, we consider where we succeeded - with student engagement and otherwise - and where we needed to improve.

\section{Discussion}

One result of our extensive preparation for using Moodle and Zoom was that we saw a significant increase in the simultaneous use of asynchronous and synchronous elements throughout the semester, which in turn enabled greater interaction in language instruction as well as more collaborative and engaging opportunities in the classroom. That is, asynchronous activities (in Moodle) were being used during synchronous sessions (Zoom). For instance, using the Etherpad Lite function in Moodle, students could write (or could continue to write) collaboratively and synchronously during online instruction via Zoom. Etherpad allowed all course participants - the students as well as the instructor - to read and to edit texts simultaneously and synchronously. Instructors could assume a facilitating role and give students feedback on their writing in various ways, whether in terms of content or grammar, depending on the activity, the language level, and other related factors. Several times, the collaborative writing among students continued after online instruction.

Other times, the students wrote collaboratively without being in an online session at the same time on Moodle. Students benefitted in many ways from such collaborative activities: By writing texts together, the task of writing in a foreign language may have been less daunting; they could 
learn from one another by reading how others had written their texts; when using Etherpad during an online session, they could benefit from real-time instructor feedback. The instructor, in turn, could identify the strengths and weaknesses of students' language skills and make appropriate adjustments for further sessions; the instructor gained a better understanding of students' interests and could use these themes for further discussion. These are just some of obvious benefits from online collaborative language learning tasks.

Each of Fleischhauer's courses required a different form of assessment. This was due to the language level as well as the class size. For example, the advanced beginner German class was assessed twice online, mid-semester and again at the end of the semester. The assessment took place online via Moodle and was administered on a particular day and time with a time limit. Given the fact that there were two other advanced beginner German courses at the LRC, Fleischhauer was able to collaborate with colleagues on the assessment collectively. Each was responsible for particular themes; these were submitted in turn by a certain date; then Fleischhauer transformed the tasks onto Moodle. The tasks covered themes in the online textbook (Braun et al., 2016). Students were asked questions that assessed their ability in reading, listening, and writing comprehension. In addition, they also had to apply their knowledge of grammar themes and new vocabulary. Working together on the assessment with colleagues saved time and yielded several fruitful discussions. The planning and implementation of the first online assessment took considerably longer than the second one. In terms of correcting the assessments, the majority of the tasks were automatically corrected in Moodle, which saved time for other instructional concerns. Students were also assessed for their oral participation in synchronous instruction as well as their completion of assignments in Moodle (homework and in-class asynchronous assignments).

Another assessment example comes from the course "Writing as an Engineer." As a final task, Fleischhauer asked students to choose one of the engineering texts that they had submitted as a graded assignment during the semester and to transform it into an oral presentation. There were seven types of texts to choose from, including an abstract, specifications, lab report, field report, recommendation, proposal, and instructions. As this was a relatively large class (twenty students at the beginning of the semester), students presented in pairs and signed up via Moodle. Fleischhauer initiated this at first through a forum on the course Moodle page. As that action did not seem to activate students, Fleischhauer then turned to Etherpad, which allowed students to see all of the organizational information at once. This proved to be the easier method. Students were given fifteen to twenty minutes to present, and presentations were held during synchronous sessions with Zoom. Students had to submit their presentation files, which Fleischhauer then uploaded to Moodle with feedback. These, in turn, could be archived in-house and saved for future reference. While groups were presenting, the rest of the class was tasked with giving the groups feedback via Moodle's feedback function. Fleischhauer developed an anonymous feedback template for the presentation and a rubric of various questions. There was a separate feedback slot for each presentation group. These slots were first activated right before the respective presentation would begin. This helped students to focus on each presentation individually. Fleischhauer later read the peer feedback and was very positively surprised by the quality and the depth with which students responded to one another. This is just another example of one of the many features available in one program.

Drucker's learning objectives for her online-only courses had different emphases than her inperson classes. As Laurillard states, "the kinds of objectives that are appropriate for [information technology-based courses] may be quite different from those you would use set if restricted to other teaching methods...There is an interrelationship between the medium and the objectives" (McKeachie, 1999). Her in-person classes normally included an opportunity for students to lead discussion about the week's text in teams of two, small-group activities, an article summary, and a written or oral final exam. They always had a participation component. However, since she herself was new to online teaching, she thought that it was too much of a burden for students to learn to teach online too. She thus shifted to oral exams instead of presentations and kept the article 
summary and the participation components but measured the latter differently. Her online-only classes had four assessments: participation during each class session, a ten- to twelve-minute oral midterm exam, a 600- to 750-word article summary, and a fifteen-minute oral final exam. For full participation credit, students had to speak at least once during the online class session and prepare the definitions of two words from the text that were new to them. They also had to write one new sentence using each word properly and say that sentence to their peers.

Drucker's focus on improving oral expression and vocabulary-building worked effectively, as the latter in particular is a simple way to measure student progress. Also, students were able to practice pronunciation and intonation and to receive immediate feedback on their speaking skills. She had to listen especially carefully to students who were unable to - or chose not to-turn their cameras on. For the midterm and final exam, she asked students who did not normally have their cameras on to verify their identity, if only briefly. Students integrated the new vocabulary words into their speaking quickly - that became evident in the final oral exams - and entered them and their definitions into each week's Moodle page glossary. Drucker's focus on speaking and reading comprehension addressed two of the four elements of the UNIcert ${ }^{\circ}$ III exam (speaking, reading comprehension, listening, and writing), which several students planned to take in September. Her classes may have helped students with the listening section of the exam as well, but she did not test listening skills specifically.

In addition to her scheduled classes, Drucker decided to add a "Sprachencafé" (language café) option for all three classes for one hour on one afternoon per week. Only one student came three times at the beginning of the semester, and two of those times were with her live-in partner, who was a student in a different university department. It was good to have the opportunity to talk with this student informally outside of class, as she did not often volunteer to speak, and she was happy to discuss light topics such as cooking and travel. Halfway through the semester, when even that single student did not log in, Drucker cancelled the Sprachencafé and heard nothing about it, including from the one student who did participate. Students may have forgotten about it, may have had a timing conflict, or were not interested in an additional ungraded period to talk to their instructor. Next semester, she will direct students interested in additional speaking practice to the all-LRC Sprachencafé that one of its student employees organizes.

Overall, students seemed engaged and receptive to the online format, and were sympathetic when the instructor or their classmates had technical errors. Sometimes classes were interrupted if the instructor lost her Internet connection, and students were notably tired if the synchronous class period lasted longer than an hour. Some students did not have webcams on their computers or the Internet bandwidth in their residences to sustain video connections and participated only through voice. Of the five conditions that Laurillard outlined in 1999 under which online teaching can take place effectively, the hardest to meet in the current pandemic is often the first: "All students have access to the technology at appropriate places and times to use it" (McKeachie, 1999). Though some local electronics stores offer student discounts, there are no university subsidies for highspeed Internet or quiet places to use them. Thus, unequal access to computers with webcams, highspeed Internet, and private study spaces where students can speak and hear will continue to hinder online learning.

Fleischhauer did not receive the results of all formal course evaluations, as four of the six courses taught had less than ten students, and instructors only receive results for classes with over ten students to preserve student anonymity (President of TU-Darmstadt, 2014). However, in the course of regular e-mail contact with students and direct feedback in synchronous sessions, she discerned some of the most important statements that students made regarding course structure. ${ }^{4}$ The students praised her ability to teach with asynchronous and synchronous tools, and felt that the pace of class was appropriate. In the advanced beginner German class, students appreciated that class always had the same structure (it might be worthy to investigate the importance of

${ }^{4}$ Fleischhauer received 2 or 3 e-mails and direct messages per week in each class with 10-15 students each, for a total of 20 messages per class during the semester and approximately 120 messages for all 6 of Fleischhauer's classes together. 
routines in digital language instruction); they also liked the mix of synchronous and asynchronous elements and having instant feedback on their progress in Moodle-based activities (with use of the Test activity). They developed a feeling of group solidarity over the course of the semester. When asked if they missed face-to-face instruction, a great majority responded by saying that they actually liked the online learning environment, because of its convenience - they did not need to travel to campus, they had time to read over materials repeatedly, and they could listen to an aural text several times in order to better understand its meaning.

Drucker did not receive quantitative results of her formal course evaluations, as her three classes had under ten students. However, she received direct feedback from time to time throughout the semester about the chosen texts and the assessment format. On another note, one student in her class felt free to suggest that a future version of the class focus on human space travel generally, including travel to the moon, to compare moon travel with Mars travel. Students in the class, perhaps because of its explicit focus on speaking, felt particularly free not only to answer to the study questions, but also to share their perspectives on how current problems in human societies might or might not be replicated on a new planet. They also felt free to disagree cordially with each other and to address each other within the Zoom meeting framework. The experience of that class illustrated how "online learning is an ideal space for enacting collegial pedagogy because of its openness" (Morris \& Taub, 2018).

Lastly, one technical problem that we did not address in April became a challenge in July: TUDarmstadt requires that hard copies of all final written exams be held in departmental offices for five years. In the busyness of the transition to wholly online teaching, and instructors' normal dependence on the administrative staff to archive paper-based exams, the fact that we would need to keep copies of final written exams was lost in the shuffle. Consequently, our administrative and IT staff had to figure out a solution for archiving electronic versions of all the final written exams with only three weeks left in the semester. The LRC's student IT assistant quickly put together a document with instructions on how to save exams within Moodle, but not before the lack of direction caused marked agitation among instructors during two weekly staff meetings. More foresight on our part would have prevented that last-minute scramble, but now we are prepared to archive electronic exams without difficulty.

To evaluate instructors' progress over the semester, the E-Learning team e-mailed a survey to all LRC instructors in March to gather their feedback about what help they needed. They e-mailed a second survey near the end of the semester and posted the results thereafter. Of the instructors who completed the surveys, twenty-nine out of thirty-five rated their Moodle skills as "much improved" or "very much improved" over the course of the semester, and thirty-one out of thirtyeight stated that their confidence regarding online teaching had improved. In March, only 10 percent of respondents had used a video conferencing tool regularly. By July, that number was 100 percent. The advantages of online teaching that LRC instructors mentioned in the survey's comments included no need to travel to the office, more intensive contact with students, and the ability to use online tools flexibly and intuitively to meet pedagogical needs. The disadvantages that they mentioned included eye strain and headaches; the increased energy and attention span to monitor multiple forms of synchronous interaction (online hands raised, text in the chat window, and making eye contact in the video chat) at once; a lack of spontaneous contact with students outside of class; and the need to manage technological problems on the spot without IT staff support on hand. Some instructors were concerned about the ease of cheating on online vs. inperson exams and requested additional future training in designing exams that would decrease opportunities for cheating and plagiarizing. A goal for many instructors was advancing their abilities in Zoom and Moodle, along with plugins like Etherpad, before the winter semester began in November.

Furthermore, our future course designs should pay greater attention to Universal Design Learning principles and to the needs of all students requiring special accommodations, including students with hearing, visual, mental health, or mobility impairments. For example, some of the 
texts that Drucker assigned had an audio listening option for students with visual impairments, but not all of them. We may consider recording the audio of our class sessions so that students can listen to them repeatedly, or using the auto-generated, searchable transcript feature on Zoom to provide hard-of-hearing students with a text that they can read later. We plan to organize a workshop with the university's disability office to develop strategies for making online language learning more accessible to all (TU-Darmstadt "Schwerbehindertenvertretung," 2020). "Making higher education accessible and meaningful for all our students," as Gannon writes, will take some additional investments of time, effort, and staff development funds (Gannon, 2020, p.6).

Lastly, the survey results also revealed changes in the relationships among LRC instructors. Before the move to online teaching, most collaboration and knowledge sharing occurred only among instructors of the same or similar languages, such as Spanish and Portuguese. Teaching wholly online and meeting regularly on Zoom via weekly staff meetings and the Stammtisch fostered regular cross-linguistic pedagogical exchanges among us, and we would like to continue them, especially in the form of online teaching peer observation and feedback. Even though such professional exchanges and burgeoning friendships were an unexpected bonus of teaching during the pandemic, the survey results showed that most instructors wished to return to face-to-face teaching as soon as possible.

Table 1

Recommendations for Improving Online Language Pedagogy in the COVID-19 Era

- Limit Introduction of New Software Programs

- Provide Ongoing Technical Education to Instructors

- Expand and Update Instructor's Language Pedagogy Skills

- Facilitate Synchronous, Multifaceted Learning for Instructors and Students

\section{Conclusion and Recommendations}

On June 10, 2020, everyone affiliated with TU-Darmstadt received an e-mail message from the university's president and the vice president of academic affairs and diversity stating that the university would maintain online teaching through the winter semester (mid-February 2021). "By deciding early on to deliver another digital semester, we wish to give all members of the university the opportunity to better prepare and plan the upcoming semester" (Brühl \& Warzecha, 2020). An extension of online teaching into summer semester 2021 was then announced on December 3, 2020 (Hufeisen, 2020b). It remains unclear how long the phase of pure digital language instruction in German institutions of higher education will last. At this point in time, we simply do not know how COVID-19 will reshape higher education in the short or long term. But for now, based on our experiences from teaching our first semester wholly online, we put forward the following four points to consider for further development: limiting new software programs, ongoing technical education, ongoing language pedagogy development and the facilitation of synchronous, multifaceted learning.

First, we suggest that instructors limit new software programs used for the planning and implementation of online language learning. Using programs that already exist and that will most likely receive funding in the future ensures that neither instructors nor students have to learn and to navigate new software programs every semester. Using these programs repeatedly facilitates synchronous and asynchronous communication on various levels: among colleagues, from teachers to students, and from student to student.

Second, as we further develop our skills in online teaching, it is imperative that the dialogue, technical education, and training among language instructors within and across languages must continue via ongoing one-on-one communication, institutional support for the Center's E-Learning team, and center-wide ongoing learning programs. The exchange of ideas, experiences, and issues related directly to the language-learning context has helped us collectively to improve the quality 
and diversity of our work. Furthermore, LMS software is updated constantly, and it is critical that we stay up-to-date on what new functions are available that can best support student learning at different levels. General guides to software tools or applications intended for the digital classroom may be initially helpful; however, they alone cannot meet or replace the individual instructional needs of the language learner and the language instructor.

Third, technology is essential for the digital classroom; however, it remains secondary to the didactics of language learning and ongoing language pedagogy development. As we continue to explore new ways of integrating digital tools into the language learning classroom, whether these be asynchronous or synchronous, we must remember to question the relevance of each tool for the language learner(s) and keep in mind what language learning goals we have in mind for them (Russell \& Murphy-Judy, 2021). The digital classroom can enable us to go beyond the traditional two-tiered framework of oral and written language production. In a synchronous setting, the use of symbolic communication tools such as digital pens, stamps, and reactions allows instructors to engage learners in new ways with them and with their classmates.

Finally, such tools can enable students as well as instructors to communicate on various levels at the same time, and we must facilitate synchronous, multifaceted learning. In a synchronous setting, while students listen and read, they also can react and actively participate, even while someone else is talking. This example would be unheard of in an analog setting. Such situations in which communicative multitasking takes place rightly pose challenges to instructors and students alike; however, they can also engage learners in a way that they can see how language learning in a digital setting can be as equally meaningful as in an analog classroom. It is possible to activate all learners, on various levels, in different ways, in a digital setting. As we continue to orient ourselves in a digital setting due to the current pandemic situation, we need to stay open to new ways of communicating with one another and to explore the possibilities the digital language learning setting has to offer. "Not only must we insist on remaining - or becoming again - active voices in what education looks like in a digital world, but we must also consider ourselves agents, advocates for teaching and learning that we know to be pedagogically sound" (Morris \& Taub, 2018). As instructors, we should see synchronous learning as more than just a digital replicate of learning face-to-face.

\section{References}

Arbeitskreis der Sprachenzentren an Hochschulen (AKS) e.V. - UNIcert® Kommission. (2017, Autumn). Niveaustufenbeschreibung Englisch, UNIcert@-Stufen Basis, I-V [Description of English Language Levels, UNIcert $\AA^{\circledR}$ Level Basis I-IV]. https://www.unicert-online.org/wp-content/uploads/2019/04/ englisch_2017.pdf

Braun, B., Doubek, M., Fügert, N., Kotas, O., Langermann, M. M., Curcio, M. N., Sander, I., Schäfer, N., Schweiger, K., Trebesius-Bensch, U., and Walter, M. (2016). DaF kompakt neu B1 [New Compact German as a foreign language B1]. Klett.

Brühl, T., Efinger, M., \& Warzecha, H. (2020, March 15). Klausuren und präsenzlehrveranstaltungen werden $a b$ sofort ausgesetzt [Examinations and face-to-face courses will be suspended immediately]. E-mail message to TUDarmstadt.

Brühl, T. \& Warzecha, H. (2020, June 10). “Courses in the 2020/2021 Winter Semester.” E-mail message to TU-Darmstadt.

Clandfield, L. \& Hockly, N. (2017). Teaching online: Tools and techniques, options and opportunities. Delta Publishing.

Council of Europe. (2020). Global scale-table 1 (cefr 3.3): Common reference levels. https://www.coe.int/en/web/common-european-framework-reference-languages/table-1-cefr-3.3common-reference-levels-global-scale

Der Spiegel [The Mirror]. (2020, March 16). EU schließt außengrenzen ab dienstagmittag [EU closes external borders on tuesday morning]. https://www.spiegel.de/politik/ausland/coronakrise-eu-schliesstaussengrenzen-ab-dienstagmittag-a-831a6255-436d-46d2-8ccd-1e4564225e3e

Gannon, K. M. (2020). Radical hope: A teaching manifesto. West Virginia University Press. 
Gehring, W. (2018). Fremdsprache Deutsch unterrichten: Kompetenzmethoden für DaF und DaZ [Teaching German as a foreign language: Competence methods for German as a foreign language and German as a second language]. UTB.

Hufeisen, B. (2020a, March 16). "Corona-Rundmail 02: Protokoll Praesidiumssitzung" [Corona Group Mail 02: Executive Council Meeting Minutes]. E-mail message to SPZ Angestellte [HRC Employees].

Hufeisen, B. (2020b, December 5). "Corona-Rundmail 20" [Corona Group Mail 20]. E-mail message to SPZ Angestellte [HRC Employees].

Kontinuum: Wissenschaftliche Weiterbildung an der TU Darmstadt [Continuum: Advanced Scientific Education at TU-Darmstadt]. (2017, April 4). Moodle an der TU Darmstadt: Handreichung [Moodle at TUDarmstadt (Handout)]. https://www.tudarmstadt.de/media/dezernat_ii_wb/kontinuum/veroeffentlichungen/Anhang_6_Moodle_Handbuch. pdf

McKeachie, W. J. (1999). McKeachie's teaching tips: strategies, research, and theory for college and university teachers. Houghton Mifflin.

Morris, S. M. \& Stommel, J. (2018). An urgency of teachers: The work of critical digital pedagogy. Hybrid Pedagogy Inc.

Morris, S. M. \& Taub, L. (2018, February 16). Ethical online learning: Critical pedagogy and social justice. https://hybridpedagogy.org/ethical-online-learning/

Nilson, L. B., \& Goodson, L. A. (2018). Online teaching at its best: Merging instructional design with teaching and learning research. Josey-Bass.

Open University. (2018). The First Ten Years 1969-1979. https://www.open.ac.uk/library/digitalarchive/exhibition/53/theme/2/page/3

President of TU-Darmstadt. (2021, January 28). Hygiene and Infection Control Concept of TU Darmstadt for SARS-CoV-2.

https://www.intern.tudarmstadt.de/media/dezernat_iv/neu_dokumente_/corona_1/Hygiene_and_infection_control_concept _Version_1.6_28_January_2021.pdf

President of TU-Darmstadt. (2020, August 11). Richtlinien für den bereich der lehrveranstaltungsevaluation der Technischen Universität Darmstadt [Guidelines for the area of course evaluation at the Technical University of Darmstadt]. https://www.hda.tudarmstadt.de/media/hda/evaluation_1/Evaluationsrichtlinie_gueltig_ab_01102014.pdf

Russell, V. \& Murphy-Judy, K. (2021). Teaching language online: a guide for designing, developing, and delivering online, blended, and flipped language courses. Routledge.

Stommel, J. (2020, March 19). The human work of higher education pedagogy. https://hybridpedagogy.org/thehuman-work-of-higher-education-pedagogy/

Stommel, J., Friend, C., \& Morris, S. M. (2020, March 31). An open letter on the future of hybrid pedagogy. https://hybridpedagogy.org/an-open-letter-on-the-future-of-hybrid-pedagogy/

TU-Darmstadt. (2020). Application and admission for international degree-seeking students. https://www.tudarmstadt.de/studieren/studieninteressierte/internationale_studieninteressierte/bewerbung_und_zulas sung_international/index.en.jsp

TU-Darmstadt. (2020). Facts and figures. https://www.tu-darmstadt.de/universitaet/index.en.jsp

TU-Darmstadt. (2020). Schwerbehindertenvertretung [Representative for severely disabled persons]. https://www.schwbv.tu-

darmstadt.de/schwerbehindertenvertretung/die_vertrauenspersonen/Index.de.jsp

TU-Darmstadt E-Learning Arbeitsgruppe [TU-Darmstadt E-Learning Team]. (2020). Lehrveranstaltungen online durchführen [Conduct Courses Online]. https://www.e-learning.tudarmstadt.de/online_lehre/index.de.jsp

Van Overmeire, B. (2018, March 20). Opening the classroom: ownership and engagement. https://hybridpedagogy.org/opening-the-classroom-ownership-and-engagement/. 